Environment

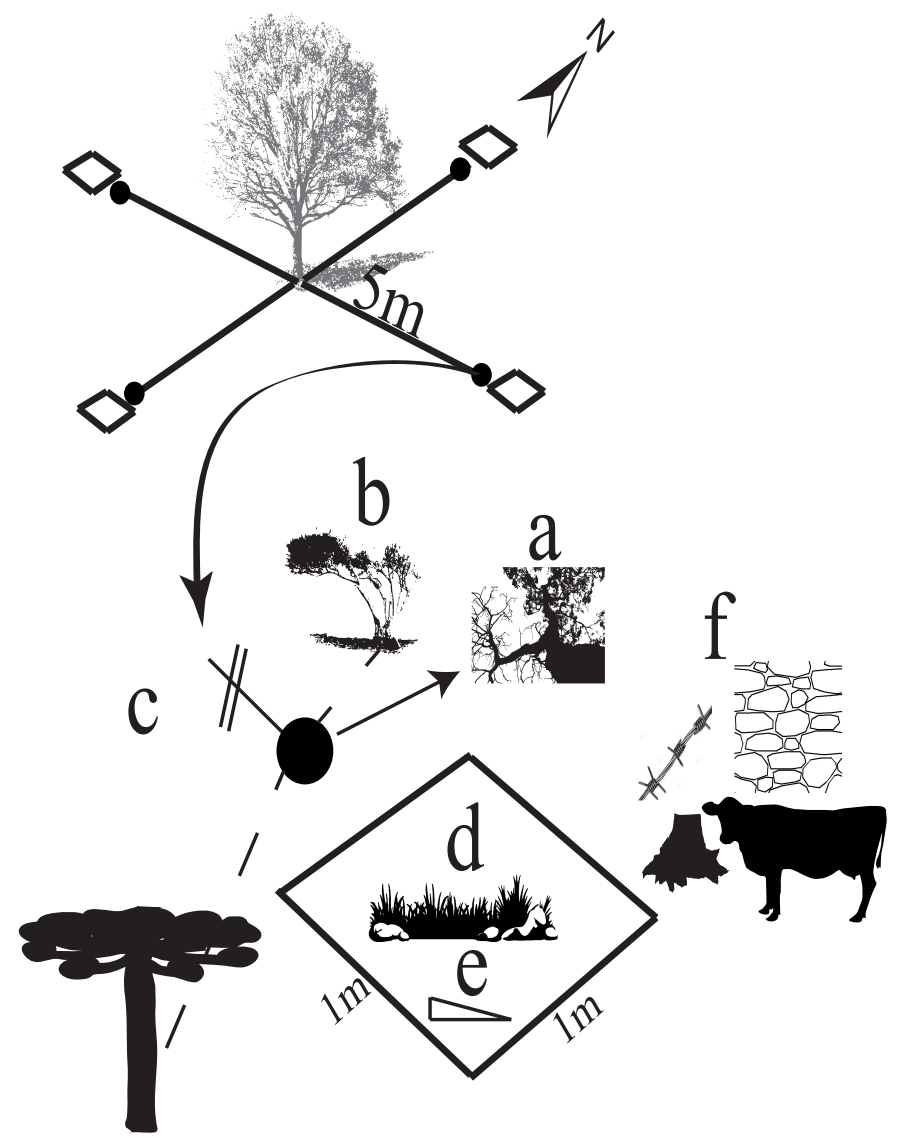

a: canopy coverage;

b: shrub distance, height and DAH;

c: tree distance, height and DAB;

d: ground coverage (e.g. green, rock);

e: inclination;

f: human and livestock evidences
Demography
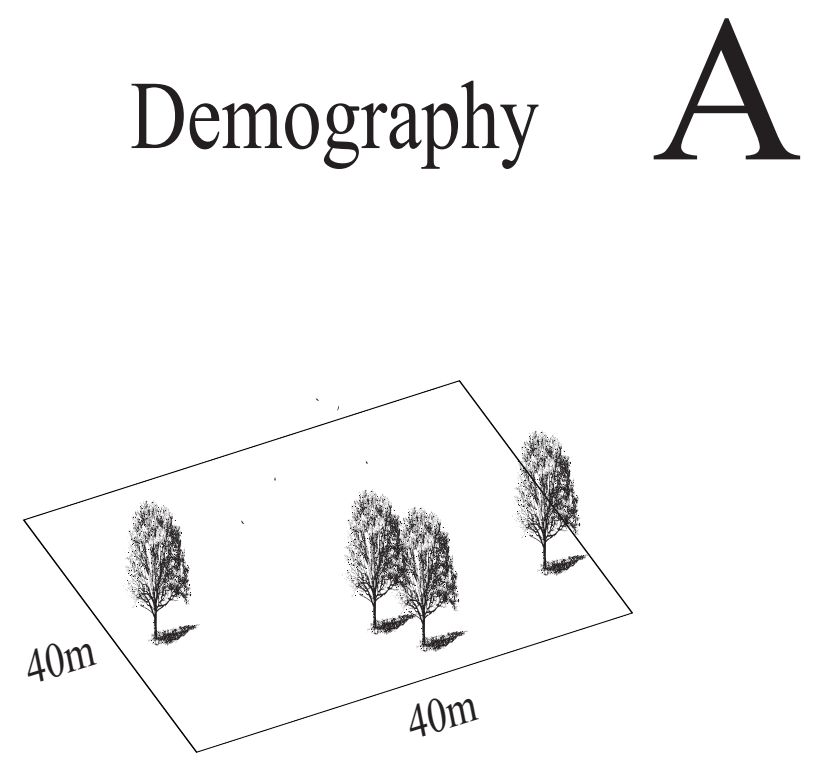

\section{Landscape}

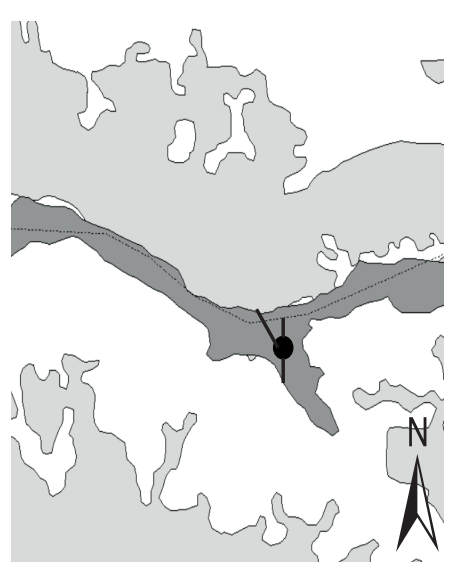

\title{
Domestication evidence
}
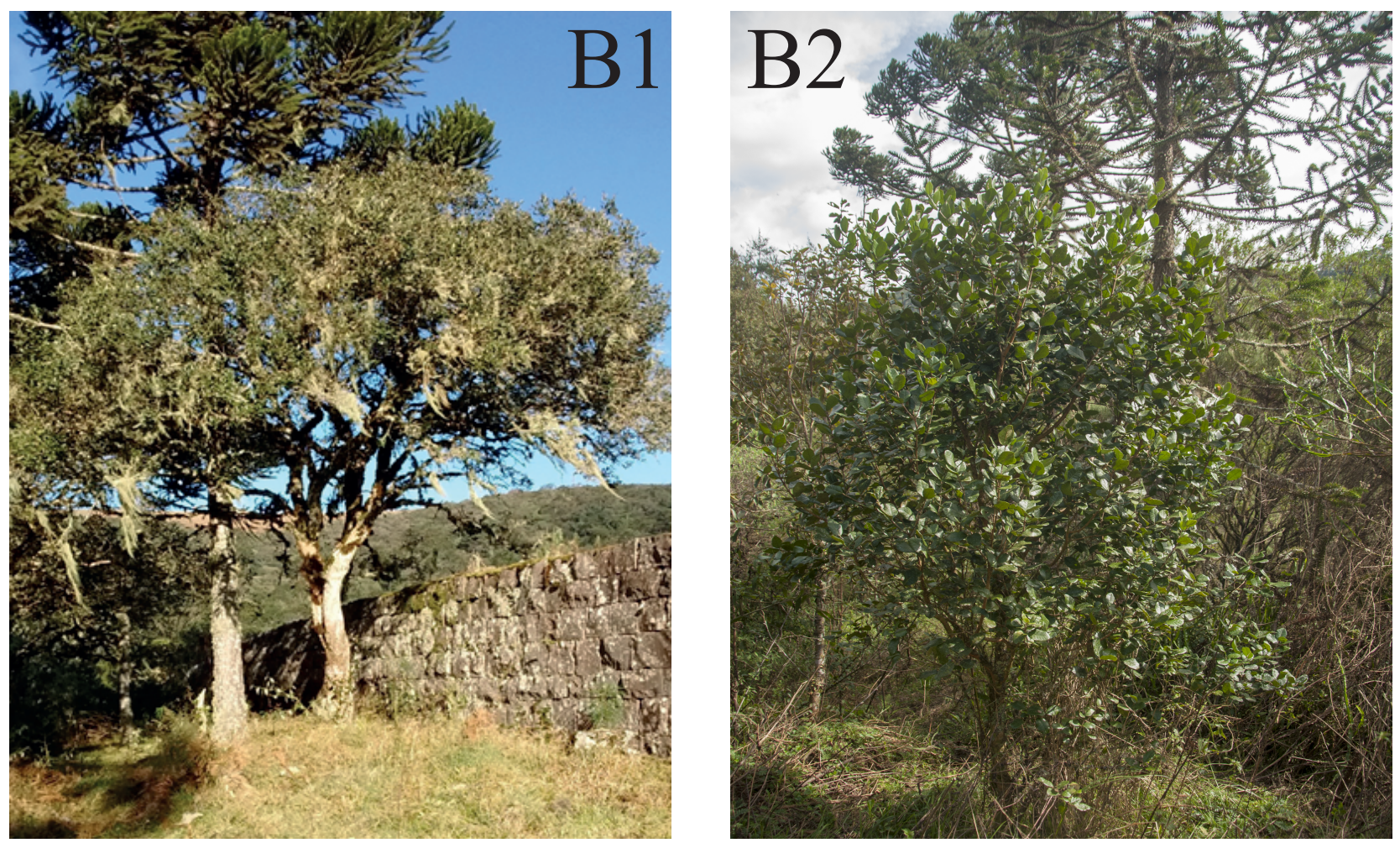